\title{
Degradation Monitoring of Repeated Cooking Oil Using Capacitive Inter-digital Electrode(IDE) Sensor
}

\author{
Mohd Faizul Md Idros ${ }^{1 *}$,Nur Syafiqah Binti Ramli ${ }^{1}$, Puteri Sarah Mohamad Saad ${ }^{2}$, Syed Abdul Mutalib \\ AlJunid ${ }^{1}$, Abdul Hadi Abdul Razak ${ }^{1}$, Abdul Karimi Halim ${ }^{1}$ \\ ${ }^{1}$ Electronic Architecture and Application Research Group (EArA) \\ ${ }^{2}$ NANO-ElecTronic Centre (NET) \\ Faculty of Electrical Engineering, UniversitiTeknologi MARA, \\ Shah Alam, Selangor, MALAYSIA \\ faizul_san287@uitm.edu.my
}

\begin{abstract}
Repeated use of cooking oil had been proven hazardous due to degradation process that contributes to the formation of polar compounds in the oil. In this study, a capacitive sensing method utilizing inter-digital electrode (IDE) design was built to assess the cooking oil degradation. The capacitance sensor plate was designed to assess the cooking oil degradation at several heating time intervals by measuring the changes on its electrical impedance. The IDE sensor has the advantages of being easy to build and highly sensitive. Besides, the IDE sensor was designed using IDE platform. Then the oil was divided into five samples, where each sample contained $150 \mathrm{ml}$. The sensor is designed as a direct measurement of the overall quality of the used oil as compare to that of the un-used oil. Lastly, the capacitance measurement will be compared with the time use and frequency. This study finds that the value of capacitance was inversely proportional due to the time use and frequency.
\end{abstract}

Key words : Capacitance, inter-digital electrodes, degradation monitoring, cooking oil

\section{INTRODUCTION}

The overused oil may also contain chemical substances which are detrimental to health. Improperly stored used cooking oil may allow bacteria to feed on the leftover food particles and potentially fatal form of food poisoning. Interactions between food and frying oil are an important aspect to investigate as to understand the deteriorative changes in frying oils. It has been reported earlier that more than $90 \%$ of the lipids in fried food came from the frying oil while more than $85 \%$ of the lipids in pre-fried food were released into the cooking oil [1]. The condition of cooking oil can affect food flavor, texture, and color since the oil acts as a medium of heat transfer. Subsequently, the change in the cooking oil quality will lead to changes in food taste. Moreover, using cooking oil continuously or repeatedly without monitoring and controlling the quality can affect human health.

Numerous researches done on evaluating oil quality including a sensor development and monitoring system for engine oil [2-4]. A technique used to include image analysis to determine the TPC, Fourier transform infrared (FTIR) to differentiate between good and unacceptable oils, and column chromatography to measure the TPC percentage in the oil. Moreover, the previous project was used Digital Image Processing (DIP) to measure the quality of cooking oil. This method is estimate of quality analysis in oil image by extracting the features like entropy, mean, average energy and variance using image processing techniques and feature extracting modeling. Besides, this method needs to deal with the portioning of images into different parts or segments to extract the information. Analog and Digital Image Processing are two types of approaches used for image processing which can be used in hard copies such as prints and photos[5]. Furthermore, there are researchers were using the dielectric constant metric method to observe the quality of the cooking oil. This method was based on combination of the internet of things, electronic and computer technology as to cater for the research need. Moreover, the measurement modal was referring to dielectric constant of cooking oil and later it was projected as TPC of the cooking oil which is inverse proportional to the oil quality [6].This method focusing on capacitance measurement.

On the other hand, the main limitation of DIP is that if the object size is smaller than the pixel size, then it cannot be applied efficiently. This is due to the one pixel can contain two or more objects. Moreover, Khaled et.al states that there are many tools and kits that can be used to determine oil degradation such as Vibro Viscometer, Testo 270 and Ebro FOM 310 but there are some limitations such as suitability for different oil types and complex calibration [7].As a solution, an inter-digital capacitance sensor was built recently to assess the cooking oil degradation [8-9]. However, capacitive sensing methods are time consuming as well as laborious to be performed. It needs faster and easier analytical technique to assess the response from a sample of cooking oil.

As reported in [10-18], an influence of oil quality on the frequency dependence of the dielectric property was used to gather basic data to support the quality assessment system of oil in the fried food industry. Therefore, the purpose of this work is to characterize an IDE sensor suitability for monitoring the degradation of frying oil after certain repeating number usage in a very low cost. The performance result of IDE sensor against the frying oil will be used as reference to interface with a controller system for portable device application in future.

\section{METHODOLOGY}

This work comprises of four important stages which are method use, sample preparation, Inter-digital Electrode (IDE) sensor design, and experimental setup. The detail of the stages will be highlighted in the respective part. 


\section{A. Method Use}

A capacitive sensing method was used to measure the parameter in this study. This method is a sensing method to detect, count, or classify Nano liter droplets, cells, or other micro particles by measuring the difference in the strength between a pair of electrically charged and isolated conductors.

\section{B. Sample Preparation}

In this study, Buruh Cooking Oil was used as samples. This cooking oil was the preferred choice for discerning consumers who demand value and quality. The oil was divides into 5 samples with each sample contained $150 \mathrm{ml}$. The sample was divided according to how many times it was used; unheated, first time heated, second time heated, third time heated and fourth time heated. The heating time for all samples was range from 0 to 15 minutes for each session. All samples were heated at $180 \pm 3^{\circ} \mathrm{C}$ as recommended by [13]. About 200 grams French fries was fried for every session.

\section{Inter-digital Electrode (IDE) SensorDesign}

A capacitive sensing method was developed using IDE model as to evaluate the degradation of cooking oil. Moreover, the IDE sensors were widely used in sensing pressure, acceleration, deformation, displacement, and position. On top of that, the IDE configurations having many advantages compared to the other configurations including flexible in design, ease to fabricate, no moving parts, low cost, and one-side access to the sensing layer as highlighted by [15].

The schematic of IDE sensor is shown in Figure1.

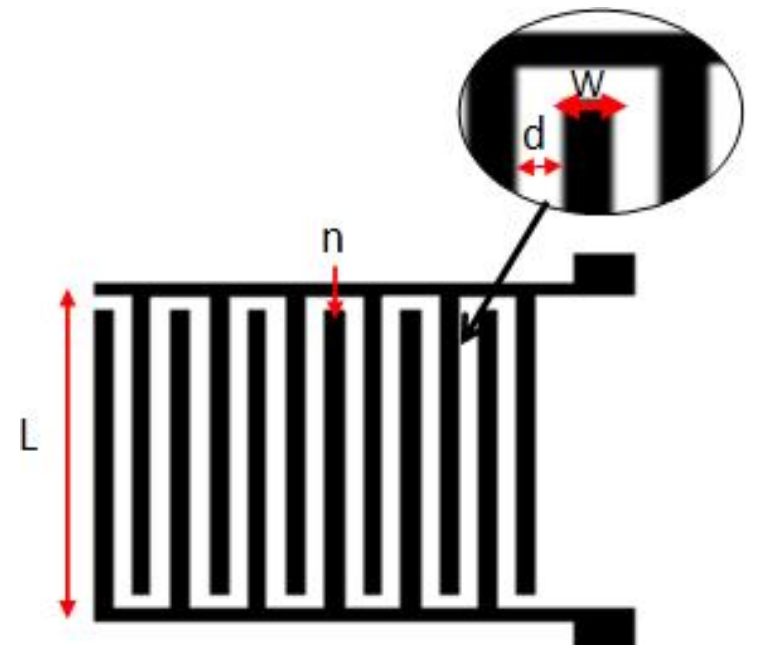

Figure 1: Schematic for IDE sensor

As depicted in Figure 1, the IDE sensor schematic comprises of the two part of the unconnected line and the sensor parameters include the electrodes finger,n; the electrode width, w; the distance between two poles, $\mathrm{d}$; and the length of electrode, L. The constructed IDE sensor is shown in Figure 2.

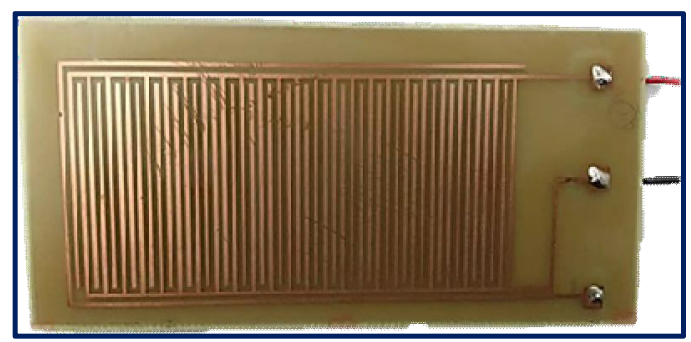

Figure 2:FR4 based IDE sensor

As shown in Figure2,theIDEsensors used in this study is based on Printed Circuit Board (PCB) FR4 technology. There were five different IDE sensors based on FR4 were used in this study. The differences are the number of fingers for each sensor, electrode width and electrode height.

The differences for each sensor in term of width, length, area and number of electrodes recorded in Table I.

\begin{tabular}{ccccc} 
& \multicolumn{4}{c}{ TABLE I: Differences for Each IDE Sensor } \\
\hline Sensor & $\begin{array}{c}\text { Width, W } \\
(\mathrm{cm})\end{array}$ & $\begin{array}{c}\text { Length, L } \\
(\mathrm{cm})\end{array}$ & $\begin{array}{c}\text { Area, A } \\
\left(\mathrm{cm}^{2}\right)\end{array}$ & $\begin{array}{c}\text { No of } \\
\text { fingers, } \mathrm{n}\end{array}$ \\
\hline 1 & 0.1 & 5 & 0.5 & 24 \\
2 & 0.01 & 3.5 & 0.035 & 31 \\
3 & 0.01 & 3.5 & 0.035 & 23 \\
4 & 0.01 & 3.5 & 0.035 & 15 \\
5 & 0.01 & 1.5 & 0.015 & 4 \\
\hline
\end{tabular}

As tabulated in Table 1, Sensor 2 has more numbers of fingers as compared to other sensors. On the other hand, the sensor's functionality can be described as

$$
A=\frac{k E o A}{d}(1)
$$

Where $\mathbf{k}$ is the dielectric constant of the oil between two poles; Eois the dielectric constant for free space, Ais the usable area of plate; and $d$ is the distance between two poles.

\section{Experimental Setup}

The setup of the experiment is very important as to ensure the result meet the requirement. Therefore, there are some planning and important procedure need to be followed. The flowchart of the experimental setup is shown Figure3. 


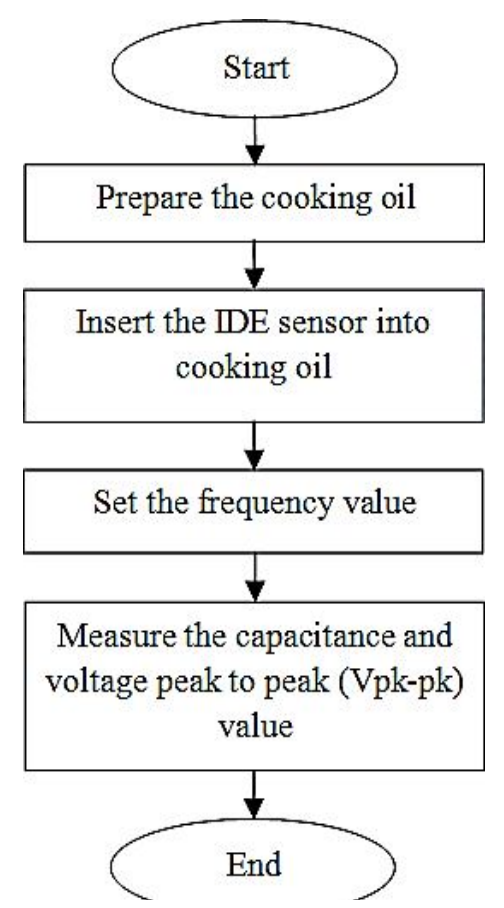

Figure 3: Flowchart of the experimental setup

As depicted in Figure 3, the flowchart shows the process from the beginning until the completion of experiment. In the first step, the equipment for this experiment was setup involved the function generator, oscilloscope, and multimeter. The input voltage was set at $10 \mathrm{~V}$ and the IDE sensor was inserted into the cooking oil. Next, four different frequencies; $10 \mathrm{~Hz}$, $50 \mathrm{~Hz}, 100 \mathrm{~Hz}$ and $1 \mathrm{kHz}$ were supplied to the IDE sensor from function generator. Then, the capacitance and peak to peak voltage value were measured. The value of the capacitance will be compared with the different quality of oil based on numbers used and frequency supplied. The overall setup of the experiment is shown in Figure 4.

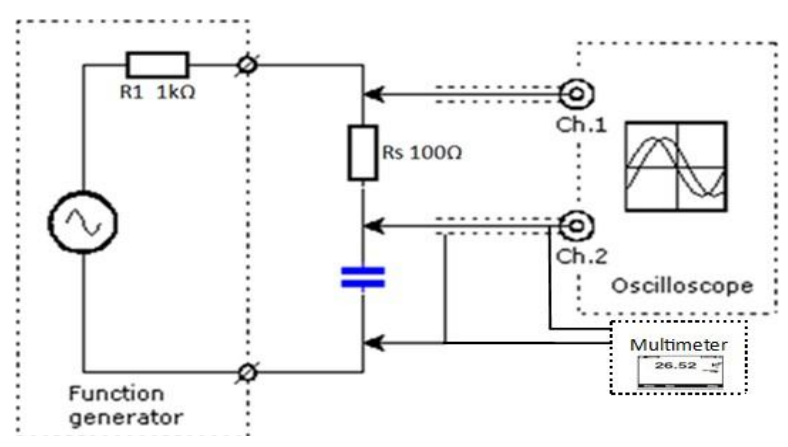

Figure 4: Arrangement of equipment for capacitance measurement with sine wave voltage

As shown in Figure 4, the function generator, IDE sensor and two resistors; R1 and Rs are connected in series. The oscilloscope was connected across the Rs and multimeter was connected across the IDE sensor.
Both R1 and Rs were set at $1 \mathrm{k} \Omega$ and $100 \Omega$. The input signal from the function generator was set as sine wave signal. Specifically, the output was monitored and measured from the oscilloscope [18].

\section{RESULT ANDDISCUSSION}

\section{A. Relationship Between Time of Frying and Capacitance Measurement}

Figure 5, 6, 7 and 8 shows the graph frying times affected the capacitance value. Five oil samples underwent the same method of experiment to determine its capacitance.

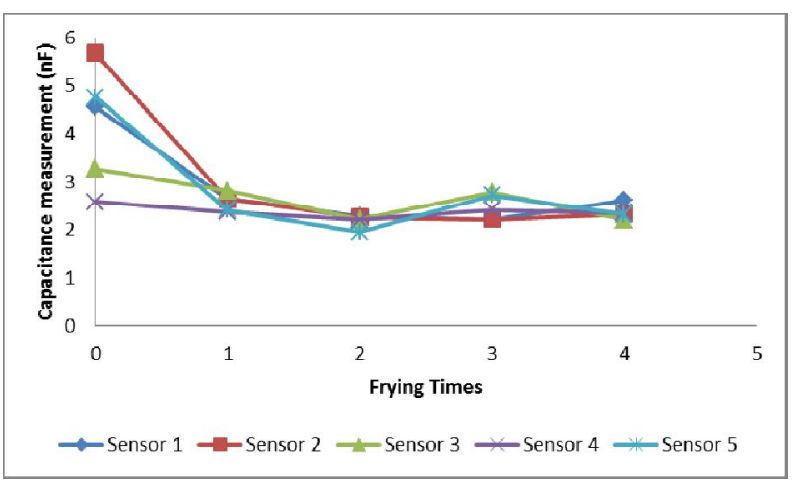

Figure 5: Capacitance Measurement at Frequency 10Hz

The graph in Figure 5 shows the capacitance result when the cooking oil was measured with $10 \mathrm{~Hz}$ of frequency supplied. It shows that Sensor 2 was presented the concave up decreasing of value of capacitance. But the capacitance value for the fourth time frying was increased up to $2.330 \mathrm{nF}$.

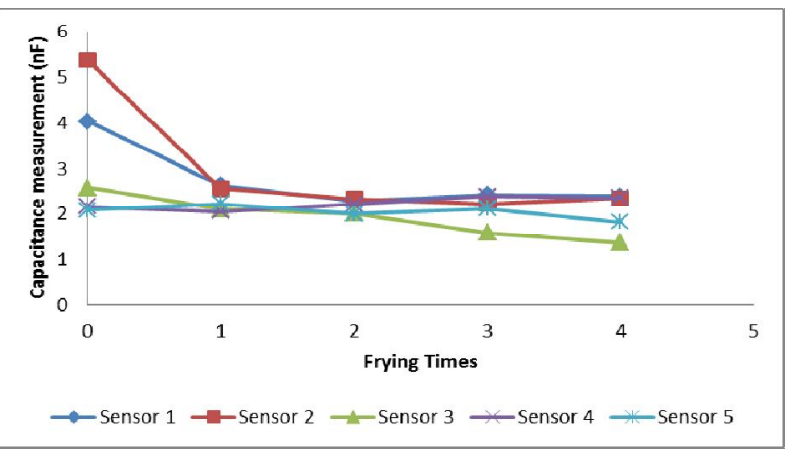

Figure 6: Capacitance Measurement at Frequency $50 \mathrm{~Hz}$

Figure 6 shows that there was no major change at frequency of $50 \mathrm{~Hz}$, especially for sensor 5 . Sensor 2 recorded extremely decreased for the capacitance value from $5.371 \mathrm{nF}$ to $2.547 \mathrm{nF}$. 


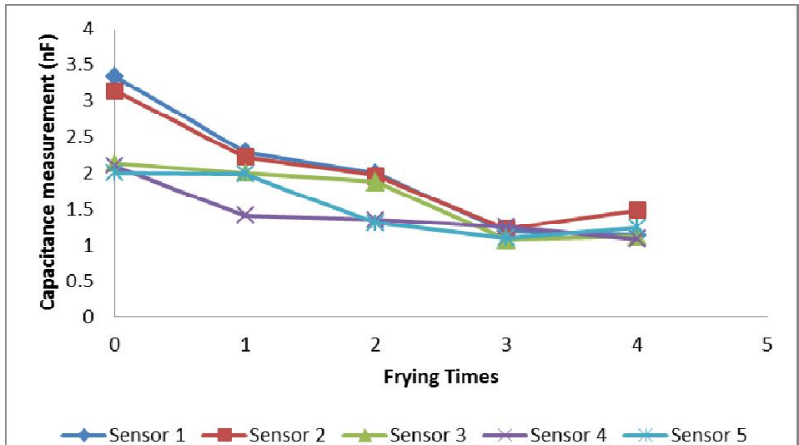

Figure 7: Capacitance Measurement at Frequency $100 \mathrm{~Hz}$

The result running at $100 \mathrm{~Hz}$ looks unstable as tabulated in Figure 7. The decreasing pattern was recorded for the non-used sample until the third time frying, before it increased at fourth time frying. The same pattern recorded by all the sensors.

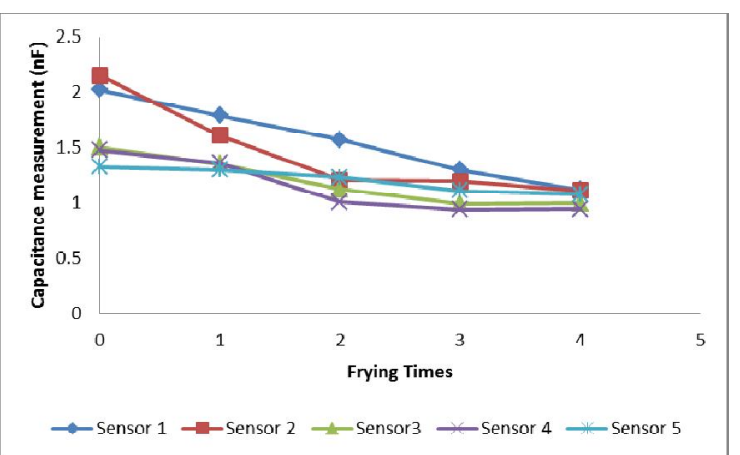

Figure 8: Capacitance Measurement at Frequency $1 \mathrm{kHz}$

Figure 8 tabulated the value of capacitance when supplied with frequency of $1 \mathrm{kHz}$. As shown in Figure 8 , the capacitance value recorded for the fourth time frying for all sensors we real most similar in the range between $1120 \mathrm{nF}$ and $1.097 \mathrm{nF}$.

Moreover, the Sensor 2 is more sensitive than the other sensors. As shown in the Figure 5, Figure 6, Figure 7 , and Figure 8 , all the capacitance value recorded by the sensor 2 is higher as compared to the capacitance value recorded by sensor 1 , sensor 3 , sensor 4 and sensor5. This is due to the distance between two poles of sensor 2 which is very closed compare to other sensors.

In comparison with the previous study by [10-11], the capacitance measurements data was analyzed to evaluate the deterioration of cooking oil quality which the viscosity and the Total Polar Compound(TPC) of cooking oil samples increased significantly as the frying time increased respectively. Moreover, the TPC value also increased when the capacitance measurement is decreased where higher TPC shows the quality level of cooking oil is unhealthy as reported by [7]. Therefore, this shows that sample at fourth time frying is the least healthy to be used as cooking oil.

\section{B. Relationship Between Frequency and Capacitance Measurement}

TABLE II, TABLE III, TABLE IV, TABLE V and TABLE VI represent the capacitance value measured for the five samples of cooking oil in different frequency and repeating number of frying. As recorded in the table, the value of the peak to peak voltage for both V1 and V2 measured in volts (V) were tabulated in the table. The entire sample were measured at different set of frequency range from $10 \mathrm{~Hz}$ up to $1 \mathrm{kHz}$. There are five oil samples underwent the same method of experiment to determine its capacitance value.

TABLE II: Non-frying cooking oil (virgin).

\begin{tabular}{|c|c|c|c|c|c|}
\hline \multirow[b]{2}{*}{ Sensor } & \multirow{2}{*}{ Parameters } & \multicolumn{4}{|c|}{ Frequency } \\
\hline & & $10 \mathrm{~Hz}$ & $50 \mathrm{~Hz}$ & $100 \mathrm{~Hz}$ & $1 \mathrm{kHz}$ \\
\hline \multirow{3}{*}{$\begin{array}{c}\text { Sensor } \\
1\end{array}$} & V1 (pk-pk) & 9.6 & 9.6 & 9.6 & 9.6 \\
\hline & V2(pk-pk) & 42 & 42 & 42.8 & 42 \\
\hline & $\begin{array}{l}\text { Capacitance } \\
(\mathrm{nF})\end{array}$ & 4.551 & 4.027 & 4.341 & 2.021 \\
\hline \multirow{3}{*}{$\begin{array}{c}\text { Sensor } \\
2\end{array}$} & V1(pk-pk) & 8.8 & 8.8 & 8.8 & 8.8 \\
\hline & V2(pk-pk) & 41.8 & 41.8 & 41.6 & 41.6 \\
\hline & $\begin{array}{l}\text { Capacitance } \\
(\mathrm{nF})\end{array}$ & 5.667 & 5.371 & 3.142 & 2.142 \\
\hline \multirow{3}{*}{$\begin{array}{c}\text { Sensor } \\
3\end{array}$} & $\mathrm{~V} 1$ (pk-pk) & 8.8 & 9.2 & 8.88 & 9.2 \\
\hline & V2(pk-pk) & 41.6 & 41.6 & 41.6 & 41.6 \\
\hline & $\begin{array}{l}\text { Capacitance } \\
(\mathrm{nF})\end{array}$ & 3.273 & 2.574 & 2.132 & 1.506 \\
\hline \multirow{3}{*}{$\begin{array}{c}\text { Sensor } \\
4\end{array}$} & V1(pk-pk) & 9.6 & 9.2 & 9.6 & 9.6 \\
\hline & V2(pk-pk) & 41.6 & 41.6 & 41.6 & 41.6 \\
\hline & $\begin{array}{l}\text { Capacitance } \\
(\mathrm{nF})\end{array}$ & 2.576 & 2.16 & 2.09 & 1.48 \\
\hline \multirow{3}{*}{$\begin{array}{c}\text { Sensor } \\
5\end{array}$} & V1(pk-pk) & 8.84 & 9.2 & 9.2 & 9.2 \\
\hline & V2(pk-pk) & 42.2 & 41.6 & 41.6 & 41.6 \\
\hline & $\begin{array}{l}\text { Capacitance } \\
(\mathrm{nF})\end{array}$ & 4.761 & 2.083 & 1.994 & 1.324 \\
\hline
\end{tabular}

TABLE II recorded the lists the capacitance value during non-frying where the value of capacitance for sensor 2 was higher at frequency $10 \mathrm{~Hz}$ at $5.667 \mathrm{nF}$ and decrease to $2.142 \mathrm{nF}$ for the supplied frequency of $1 \mathrm{kHz}$.

\begin{tabular}{|c|c|c|c|c|c|}
\hline \multirow{2}{*}{ Sensor } & \multirow{2}{*}{$\begin{array}{l}\text { Paramet } \\
\text { ers }\end{array}$} & \multicolumn{4}{|c|}{ Frequency } \\
\hline & & $10 \mathrm{~Hz}$ & $50 \mathrm{~Hz}$ & $100 \mathrm{~Hz}$ & $1 \mathrm{kHz}$ \\
\hline \multirow[b]{3}{*}{ Sensor 1} & V1(pk-pk) & 9.2 & 9.2 & 9.2 & 8.48 \\
\hline & V2(pk-pk) & 41.6 & 42 & 41.6 & 39.2 \\
\hline & $\begin{array}{l}\text { Capacitance } \\
(\mathrm{nF})\end{array}$ & 2.275 & 2.275 & 1.993 & 1.572 \\
\hline \multirow[b]{3}{*}{ Sensor 2} & V1(pk-pk) & 8.48 & 8.48 & 8.8 & 9.2 \\
\hline & V2(pk-pk) & 41.6 & 42.4 & 41.6 & 41.6 \\
\hline & $\begin{array}{l}\text { Capacitance } \\
(\mathrm{nF})\end{array}$ & 2.265 & 2.331 & 1.959 & 1.207 \\
\hline \multirow[b]{3}{*}{ Sensor 3} & V1(pk-pk) & 9.2 & 9.2 & 9.2 & 8.8 \\
\hline & V2(pk-pk) & 41.6 & 41.6 & 41.6 & 41.6 \\
\hline & $\begin{array}{l}\begin{array}{l}\text { Capacitance } \\
(\mathrm{nF})\end{array} \\
\end{array}$ & 2.212 & 2.001 & 1.87 & 1.125 \\
\hline \multirow{3}{*}{ Sensor 4} & V1(pk-pk) & 9.6 & 9.2 & 9.6 & 8.8 \\
\hline & V2(pk-pk) & 34.4 & 42 & 41.6 & 41.6 \\
\hline & $\begin{array}{l}\text { Capacitance } \\
(\mathrm{nF})\end{array}$ & 2.209 & 2 & 1.345 & 1.008 \\
\hline \multirow[b]{3}{*}{ Sensor 5} & V1 (pk-pk) & 9.2 & 8.8 & 9.6 & 9.2 \\
\hline & V2(pk-pk) & 41.6 & 42 & 41.6 & 41.6 \\
\hline & $\begin{array}{l}\text { Capacitance } \\
(\mathrm{nF})\end{array}$ & 1.951 & 1.992 & 1.3 & 1.231 \\
\hline
\end{tabular}

As recorded in TABLE III, sensor 1 at the frequency of $10 \mathrm{~Hz}$ recorded the higher value of capacitance with $2.275 \mathrm{nF}$ and the lowest reading at frequency of $1 \mathrm{kHz}$ is recorded by sensor 4 with $1.008 \mathrm{nF}$. 
Mohd Faizul Md Idros et al., International Journal of Emerging Trends in Engineering Research, 8(9), September 2020, 6177 - 6182

TABLE IV: Twotimes frying oil

\begin{tabular}{|c|c|c|c|c|c|}
\hline \multirow{2}{*}{ Sensor } & \multirow{2}{*}{ Parameters } & \multicolumn{4}{|c|}{ Frequency } \\
\hline & & $10 \mathrm{~Hz}$ & $50 \mathrm{~Hz}$ & $100 \mathrm{~Hz}$ & $1 \mathrm{kHz}$ \\
\hline \multirow[b]{3}{*}{ Sensor 1} & V1(pk-pk) & 8.8 & 9.2 & 8.8 & 8.8 \\
\hline & V2(pk-pk) & 41.6 & 41.6 & 41.6 & 41.6 \\
\hline & $\begin{array}{l}\text { Capacitance } \\
(\mathrm{nF})\end{array}$ & 2.639 & 2.625 & 2.291 & 1.791 \\
\hline \multirow[b]{3}{*}{ Sensor 2} & V1 (pk-pk) & 9.2 & 9.2 & 9.2 & 9.2 \\
\hline & V2(pk-pk) & 41.6 & 41.6 & 41.6 & 41.6 \\
\hline & $\begin{array}{l}\text { Capacitance } \\
(\mathrm{nF})\end{array}$ & 2.636 & 2.547 & 2.221 & 1.613 \\
\hline \multirow[b]{3}{*}{ Sensor 3} & V1(pk-pk) & 9.2 & 8.8 & 9.6 & 9.2 \\
\hline & V2(pk-pk) & 42 & 41.6 & 41.6 & 39.2 \\
\hline & $\begin{array}{l}\text { Capacitance } \\
(\mathrm{nF})\end{array}$ & 2.813 & 2.097 & 1.995 & 1.353 \\
\hline \multirow{3}{*}{ Sensor 4} & V1(pk-pk) & 8.48 & 8.48 & 8.48 & 9.2 \\
\hline & V2(pk-pk) & 41.6 & 42.4 & 42.4 & 41.6 \\
\hline & $\begin{array}{l}\text { Capacitance } \\
(\mathrm{nF})\end{array}$ & 2.366 & 2.05 & 1.407 & 1.36 \\
\hline \multirow{3}{*}{ Sensor 5} & V1 (pk-pk) & 9.2 & 9.2 & 8.64 & 8.8 \\
\hline & V2(pk-pk) & 41.6 & 41.6 & 41.6 & 41.6 \\
\hline & $\begin{array}{l}\text { Capacitance } \\
(\mathrm{nF})\end{array}$ & 2.411 & 2.221 & 1.981 & 1.3 \\
\hline
\end{tabular}

As recorded in TABLE IV, sensor 3 produce the highest capacitance value at frequency of $10 \mathrm{~Hz}$ with $2.813 \mathrm{nF}$ and the lowest reading at frequency of $1 \mathrm{kHz}$ is recorded by sensor 5 with $1.300 \mathrm{nF}$.

TABLE V: Three times frying oil.

\begin{tabular}{|c|c|c|c|c|c|}
\hline \multirow[t]{2}{*}{ Sensor } & \multirow[t]{2}{*}{ Parameter } & \multicolumn{4}{|c|}{ Frequency } \\
\hline & & $10 \mathrm{~Hz}$ & $50 \mathrm{~Hz}$ & $100 \mathrm{~Hz}$ & $1 \mathrm{kHz}$ \\
\hline \multirow{3}{*}{ Sensor 1} & V1(pk-pk) & 9.2 & 9.2 & 9.2 & 8.8 \\
\hline & V2(pk-pk) & 41.6 & 42 & 41.6 & 39.2 \\
\hline & $\begin{array}{l}\text { Capacitance } \\
(\mathrm{nF})\end{array}$ & 2.225 & 2.414 & 1.19 & 1.299 \\
\hline \multirow{3}{*}{ Sensor 2} & V1 (pk-pk) & 9.2 & 9.2 & 9.2 & 8.8 \\
\hline & V2(pk-pk) & 41.6 & 41.6 & 41.6 & 38 \\
\hline & $\begin{array}{l}\text { Capacitance } \\
(\mathrm{nF})\end{array}$ & 2.33 & 2.224 & 1.226 & 1.199 \\
\hline \multirow{3}{*}{ Sensor 3} & V1 (pk-pk) & 9.6 & 9.2 & 9.6 & 8.8 \\
\hline & V2(pk-pk) & 34.4 & 42 & 41.6 & 39.2 \\
\hline & $\begin{array}{l}\text { Capacitance } \\
(\mathrm{nF})\end{array}$ & 2.777 & 1.579 & 1.076 & 0.988 \\
\hline \multirow{3}{*}{ Sensor 4} & V1 (pk-pk) & 9.6 & 9.2 & 9.6 & 8.8 \\
\hline & V2(pk-pk) & 41.6 & 41.6 & 41.6 & 39.2 \\
\hline & $\begin{array}{l}\text { Capacitance } \\
(\mathrm{nF})\end{array}$ & 4.141 & 2.378 & 1.258 & 0.941 \\
\hline \multirow{3}{*}{ Sensor 5} & V1(pk-pk) & 2 & 2 & 2.4 & 8.48 \\
\hline & V2(pk-pk) & 2 & 1.6 & 1.6 & 40 \\
\hline & $\begin{array}{l}\text { Capacitance } \\
(\mathrm{nF})\end{array}$ & 2.715 & 2.113 & 1.098 & 1.112 \\
\hline
\end{tabular}

As recorded in TABLE $\mathrm{V}$, sensor 4 recorded the highest reading atthe frequency of $10 \mathrm{~Hz}$ with $4.141 \mathrm{nF}$ and the lowest reading at frequency of $1 \mathrm{kHz}$ is recorded by sensor 4 with $0.941 \mathrm{nF}$.
TABLE VI: Fourtimes frying oil.

\begin{tabular}{|c|c|c|c|c|c|}
\hline \multirow[t]{2}{*}{ Sensor } & \multirow[t]{2}{*}{ Parameters } & \multicolumn{4}{|c|}{$\begin{array}{c}\text { Frequenc } \\
\mathrm{y} \\
\end{array}$} \\
\hline & & $10 \mathrm{~Hz}$ & $50 \mathrm{~Hz}$ & $100 \mathrm{~Hz}$ & $1 \mathrm{kHz}$ \\
\hline \multirow{3}{*}{ Sensor 1} & V1(pk-pk) () & 9.2 & 9.2 & 9.2 & $8 . .40$ \\
\hline & V2(pk-pk) & 42.2 & 41.6 & 41.6 & 36 \\
\hline & $\begin{array}{l}\text { Capacitance } \\
(\mathrm{nF})\end{array}$ & 4.609 & 2.377 & 1.129 & 1.12 \\
\hline \multirow{3}{*}{ Sensor 2} & V1(pk-pk) & 9.2 & 9.2 & 9.2 & 9.2 \\
\hline & V2(pk-pk) & 41.6 & 41.6 & 41.6 & 39.2 \\
\hline & $\begin{array}{l}\text { Capacitance } \\
(\mathrm{nF})\end{array}$ & 2.33 & 2.337 & 1.418 & 1.113 \\
\hline \multirow{3}{*}{ Sensor 3} & V1(pk-pk) & 9.6 & 9.2 & 9.2 & 9.6 \\
\hline & V2(pk-pk) & 41.6 & 41.6 & 41.6 & 41.2 \\
\hline & $\begin{array}{l}\text { Capacitance } \\
(\mathrm{nF})\end{array}$ & 2.217 & 1.363 & 1.119 & 0.999 \\
\hline \multirow{3}{*}{ Sensor 4} & V1(pk-pk) & 9.6 & 9.2 & 9.6 & 9.6 \\
\hline & V2(pk-pk) & 41.6 & 41.6 & 41.6 & 41.6 \\
\hline & $\begin{array}{l}\text { Capacitance } \\
(\mathrm{nF})\end{array}$ & 3.35 & 2.345 & 1.081 & 0.948 \\
\hline \multirow{3}{*}{ Sensor 5} & V1(pk-pk) & 9.6 & 9.6 & 9.6 & 9.2 \\
\hline & V2(pk-pk) & 41.6 & 41.6 & 41.6 & 41.6 \\
\hline & $\begin{array}{l}\text { Capacitance } \\
(\mathrm{nF})\end{array}$ & 2.313 & 1.812 & 1.236 & 1.097 \\
\hline
\end{tabular}

As recorded in TABLE VI, the capacitance value of $0.948 \mathrm{nF}$ recorded by sensor 4 during fourth frying time at frequency $1 \mathrm{kHz}$ and this is shows that the cooking oil has low quality at this point.

From all the recorded data, it can be concluding that capacitive reactance of a capacitor decreases when the frequency that across its plates increases. Therefore, capacitive reactance is inversely proportional to the frequency. As the frequency increase, the capacitance measurement in an unstable reading. Refer to previous study, the dipole density and electric susceptibility increased, as the amount of the fat in the oil increased as reported by [13]. This leads to the decrement of the capacitance of the cooking oil samples.

So, in this study, the suitable frequency to detect the effect of the cooking oil is below than $1 \mathrm{KHz}$. If the frequency over the $1 \mathrm{kHz}$ was set, the output on the multimeter is open loop (OL). This means the capacitance value was greater than the meter can measure. This result can also mean the capacitor has shorted.

Lastly, sensor 2 is suitable to measure the quality of the cooking oil. This is because the reading that recorded by sensor 2 was more sensitive as compared to others. Refer to TABLE II the reading for sensor to at $10 \mathrm{~Hz}$ is higher compare to reading that recorded by using sensor 1. Moreover, thenumber of fingers in the smaller area shows the higher sensitivity ofthe IDE sensor.

\section{Conclusion}

The finding from the study conclude that the IDE sensor sensitive to operate at below $1 \mathrm{kHz}$ frequency with the number of fingers in the sensor influence the sensitivity performance of the sensor. The sensitivity is proportional to the number of fingers in sensor. Moreover, the measurement of capacitance value decreased when the frying time and frequency were increased which shows that when frying time increased, then polarized molecules 
increased and there was a potential of food poisoning when it used beyond a limit. Considering the response of capacitance to IDE sensor, it has good potential for a low cost and simple way of monitoring oil degradation with the interfacing the IDE sensor with portable device will give more valuable impact to the public safety.

\section{ACKNOWLEDGEMENT}

This project was supported by UniversitiTeknologi MARA and Ministry of Higher Education Malaysia under Fundamental Research Grant Scheme (FRGS/1/2019/TK04/UITM/02/28).

\section{REFERENCES}

1. G. Bansal, W. Zhou, P. J. Barlow, H. L. Lo, and F. L. Neo, "Performance of palm olein in repeated deep frying and controlled heatingprocesses," FoodChem.,vol.121,no.2,pp.338-347,2010.

2. M. F. M. Idros, A. H. A. Razak, S A M Al Junid, S.I. Sulimanand A. K. Halim, "FPGA implementation of predictive degradation model for engine oil lifetime", IOP Conference Series: Materials Science and Engineering, Volume 341, International Conference on Applied Electronic and Engineering 2017 (ICAEE2017) 7-8 August 2017, Kuching, Sarawak, Malaysia.

3. A.D.M. Rosman, A. H. A. Razak, M. F. Azmi, S. A. M. Al Junid, A. K. Halim, M. F. M. Idros," Capability of Indium Tin Oxide as a sensing mechanism for engine oil degradation monitoring", 2016 6th IEEE International Conference on Control System, Computing and Engineering (ICCSCE).

4. MFM Idros, Sawal Hamid Md Ali, Md Shabiul Islam," Condition based engine oil degradation monitoring system, synthesis and realization on ASIC", 2014 IEEE 11th International Conference on Semiconductor Electronics (ICSE)

5. Sangareddy B.K, Soumya H.R, Shalini R.Y, Namratha H.N, ManaviH.V."Cooking Oil Quality Analysis Using Digital Image Processing", Journal of Image Processing and Artificial Intelligence, vol.4, 2018

6. R. Srivinas, Rajesh, Srivinasa, Satheesh, "Smart Cooking Oil Analyzer using Dielectric Constant Metric," Int. J. Pure Appl. Math., vol. 117, no. 17, pp. $65-70,2017$.

7. K. N. Khamil and M. A. U. C. Mood, "Dielectric sensing (capacitive) on cooking oil's TPC level," $J$. Telecommun. Electron. Comput. Eng., vol. 9, no. 3, pp. 27-32,2017.

8. Y.Peng,L.Zhao,andS.Yang,"Edible oil electrical parameters detection system design based on inter digital sensor," pp. 173-178, 2013.

9. A. Y. K. Al-Khaled, "Interdigited Electrode(IDE) For Frying OIL Degradation Assessment During Heating," Univ. Putra Malaysia, vol. 8,2015.

10. C. Inoue, Y. Hagura, M. Ishikawa, and K. Suzuki, "The dielectric property of soybean oil in deep-fat frying and the effect of frequency," J. Food Sci., vol. 67, no. 3, pp. 1126-1129,2002.
11. Y. Kang and D. Li, "Capacitance Method," in Encyclopedia of Microfluidics and Nanofluidics, D. Li, Ed. Boston, MA: Springer US, 2013, pp.1-3.

12. S. Raadnui and S. Kleesuwan, "Low-cost condition monitoring sensor for used oil analysis," Wear, vol. 259, no. 7-12, pp. 1502-1506,2005.

13. A. Y. Khaled, S. A. Aziz, and F. Z. Rokhani, "Development and Evaluation of an Impedance Spectroscopy Sensor to Assess Cooking Oil Quality," Int. J. Environ. Sci. Dev., vol. 5, no. 3, pp. 299-302,2014.

14. F. Z. Khaled, A. Y., Aziz, S. A., Ismail, W. I. W., \&Rokhani,

“CapacitiveSensingSystemforFryingOil,"CircuitsSys t.Symp.(ICSyS), 2015 IEEE Int. IEEE Explor. no. February, pp. 137-141, 2015.

15. F. Z. Khaled, A. Y., Abd Aziz, S., \&Rokhani, "Impedance Sensor Probe for Degradation Assessment of Cooking Oil," Proc. Int. Conf. Agric. Eng. Eur. Soc. Agric. Eng. Zurich, Switz., pp. 17,2014.

16. M. Irshad et al., "A miniaturized electronic sensor for instant monitoring of ethanol in gasohol fuel blends," RSC Adv., vol. 8, no. 41, pp. 22952 22962,2018.

17. H. M. Aguilar and R. F. Maldonado, "Capacitive cells for dielectric constant measurement," Phys. Educ., vol. 50, no. 6, pp. 662-666, 2015.

18. R. Minasamudram, P. Agarwal, and P. Venkateswaran, "Simulation of a Capacitive Sensor for Wear Metal Analysis of Industrial Oils," 2013 COMSOL Conf. Bangalore, no. October, p. 6,2013. 